\title{
Catadores de materiais recicláveis: a construção de novos sujeitos políticos
}

\author{
Mari Aparecida Bortoli
}

Pontifícia Universidade Católica do Rio Grande do Sul (PUC-

RS)

\section{Catadores de materiais recicláveis: a construção de novos sujeitos políticos}

Resumo: Este texto relata uma experiência no âmbito da extensão universitária, realizada junto a um grupo de catadores de materiais recicláveis para geração de trabalho e renda. A proposta teve a participação dos catadores desde a elaboração até a avaliação e constituiuse num projeto, cuja intenção foi associar as habilidades de gestão a uma ação de geração de trabalho e renda, a partir da construção de alternativas socioeconômicas, com foco na autogestão. Além de relatar os procedimentos metodológicos e apresentar os resultados da intervenção, são discutidas as condições de vida e trabalho às quais os catadores estão submetidos e a construção de espaços de discussão para construção desses sujeitos políticos.

Palavras-chave: participação, formação política, trabalho e renda.

\section{Collectors of Recyclable Materials: the Construction of New Political Subjects}

Abstract: This text reports on an experience of a university extension project, conducted with a group of collectors of recyclable materials to generate labor and income. The project had the participation of the collectors from its creation until the evaluation process and constitutes a project whose intention was to associate management abilities to an action to generate work and income, based on the construction of socio-economic alternatives, with a focus on self-management. In addition to reporting on the methodological procedures and presenting the results of the intervention, the living and working conditions to which the collectors are submit are discussed, as well as the construction of discussion spaces to help the formation of these political subjects.

Key words: participation, political education, labor and income. 


\section{Introdução}

Agnes Varda, no filme Les glaneurs et la glaneuse (2000), retrata a França moderna e mostra aqueles que vivem da recuperação dos restos e sobras, a partir de fragmentos de histórias de catadores urbanos e rurais. Do aproveitamento das sobras de batatas e maçãs para alimentação humana até a recuperação de sucatas através da reciclagem, é traçado o percurso de uma sociedade para a qual o descartável vai dos "alimentos feios" até "aqueles que vivem da recuperação das coisas".

A atividade de catar alimentos para comer e material reciclável para vender foi registrada no Brasil por Marcos Prado, no documentário Estamira (2004). Questionamentos sobre o destino do lixo e sobre a realidade insuportável à qual pessoas são submetidas atravessam o documentário, que conta a história de uma mulher que busca no lixo sentido para viver. No aterro de Gramacho, Rio de Janeiro, as pessoas são flagradas vivendo do lixo e tem no lixão seu lugar de trabalho.

Tanto no filme francês quanto no documentário brasileiro, catar alimentos e catar material para ser reciclado são atividades que se misturam, por vezes se acumulam, e estão presentes na vida de moradores de rua, de desempregados, daqueles que nunca trabalharam ou que se tornaram não empregáveis e são obrigados a se deslocarem para a informalidade ou para o trabalho por conta própria.

No Brasil, a profissão de catador de material reciclável é reconhecida e foi oficializada em 2002, pela Classificação Brasileira de Ocupações (CBO). Estima-se que no país sejam mais de 500 mil catadores de lixo. Contudo, o reconhecimento da profissão não implicou mudança nas condições de vida e trabalho dos catadores, os quais atuam sem vínculo empregatício e sem direitos, ganham, em geral, menos de um salário mínimo, disputam materiais recicláveis com seus pares, não estão inseridos nos sistemas de gestão de resíduos e enfrentam a exploração da indústria da reciclagem.

Nesse contexto, marcado pela emergência de processos e dinâmicas que contribuem para a precarização do trabalho e penalizam os trabalhadores, os catadores de materiais recicláveis iniciam seus processos de organização social e econômica e de luta por direitos. Os primeiros acontecimentos datam dos últimos anos da década de 1990 e início do século 21, nos quais foram realizados os encontros e congressos que culminaram na criação do Movimento Nacional de Catadores de Materiais Recicláveis (MNCR). Em 1999 foi realizado o Primeiro Encontro Nacional de Catadores de Papel. Em 2001 aconteceu o Primeiro Congresso Nacional de Catadores de Materiais Recicláveis, em Brasília, e em 2003 foi realizado o Primeiro Congresso Latino-Americano de Catadores de Materiais Recicláveis, em Caxias do Sul, Rio Grande do Sul. O Segundo Congresso Latino-Americano aconteceu em 2005 e, em 2006, mais de 1.200 catadores marcharam até Brasília, levando demandas ao Governo Federal e exigindo a criação de postos de trabalho em cooperativas e associações, bases orgânicas do movimento. As reivindicações dos catadores são por alimentação, moradia, condições mínimas de vida, além da inclusão no processo de gestão dos resíduos e da luta pela criação de postos de trabalho.

Boaventura de Souza Santos (2007), ao se referir a sua participação como conferencista no Sexto Festival do Lixo e Cidadania, realizado em Belo Horizonte, lembra que os catadores não desistem de lutar por uma vida digna, a partir da exigência de formas de organização e mobilização autônomas para passarem de "miseráveis comedores de lixo" a uma "ocupação profissional”. Não se pode ignorar que "outras formas de sociabilidade" emergem como iniciativas de enfrentamento da crise nas relações de produção. No entanto, muitas vezes, no dizer de Mota e Amaral (2006, p. 30) "relacionam-se com a necessidade que tem o capital, neste momento, de criar novas formas de subordinação do trabalho."

Assim, uma aproximação aos processos sociais em que se inserem os catadores de materiais recicláveis possibilita desvelar acomodações, resistências e lutas, bem como as expectativas de mudança das condições de vida e trabalho dessa população. Com esta intenção, o objetivo deste texto é relatar uma experiência de intervenção no âmbito da geração de trabalho e renda, realizada junto a um grupo de catadores de materiais recicláveis do Núcleo Habitacional Santa Bárbara (NHSB), no município de Cruz Alta, Rio Grande do Sul, entre os anos de 2006 e 2008 . De caráter qualitativo, o estudo traz informações e a possibilidade de conhecer os sujeitos envolvidos em ações realizadas a partir de um projeto de extensão universitária ${ }^{1}$.

A construção de espaços de questionamento e tensionamento das relações econômicas, políticas, 
culturais e sociais e a compreensão histórica das instituições, organizações e modos de viver dos catadores de materiais recicláveis mostram o surgimento destes novos sujeitos políticos. Faz-se necessário reconhecer que na execução da intervenção aqui apresentada não se procurou avaliar o retorno econômico, mas sim evidenciar as contribuições das ações desenvolvidas para a formação política e para a transformação das realidades vividas por estes trabalhadores. Sendo assim, neste relato ganha importância o papel do catador de material reciclável, o qual protagonizou esse processo de organização econômica e de participação social desde a elaboração da proposta até a avaliação dos resultados.

\section{Geração de trabalho e renda: um cenário desafiador}

A geração de trabalho e renda está relacionada ao incentivo ao associativismo, ao cooperativismo, ao empreendedorismo e ao trabalho em equipe, habilidades de gestão que tendem a possibilitar ao trabalhador a tomada de decisão. Se, por um lado, essas formas de gestão e organização do trabalho respondem pela sobrevivência dos trabalhadores, por outro, estão associadas ao regime de acumulação flexível, o qual tem ditado as regras para a constituição de instrumentos de regulação social, afinados com as necessidades de coesão do sistema de reprodução do capital.

$\mathrm{Na}$ implementação dessas formas de gestão do trabalho, torna-se comum a presença de populações que foram, de certa forma, afastadas das possibilidades de trabalho e são "capturadas" em estratégias que, ao aproximá-las do trabalho, as faz reféns de práticas que competem para a manutenção e conservação das relações sociais instituídas. Esta realidade se constitui num cenário desafiador tanto para a compreensão quanto para a intervenção, pois, em certa medida, como lembram Yazbek e Silva (2005, p. 31) "implica no deslocamento para a sociedade das tarefas de enfrentar a pobreza e a exclusão social."

Porém, frente a um quadro de 180 milhões de desempregados e quase três bilhões de pessoas que vivem na pobreza no mundo, conforme registra Yazbek (2005), seria "perverso recusar a diversidade das inspirações e das ações de intervenção na realidade problemática". Visão compartilhada por Martins (2002, p. 9), para quem:

Tudo de sensato e fundamentado que se fizer e propuser no sentido de acelerar a inclusão social e política das populações pobres no processo de desenvolvimento econômico, para com ele compatibilizar o ritmo do desenvolvimento social, será historicamente bem-vindo.

\section{Aproximação e construção de estratégias metodológicas}

Com a intenção de associar as habilidades de gestão a uma ação de geração de trabalho e renda a partir de uma demanda dos catadores do município de Cruz Alta/RS, foi elaborado um projeto de extensão universitária, a partir de um Edital do $\mathrm{CNPq}^{2}, \mathrm{o}$ qual previa apoio ao desenvolvimento de tecnologias sociais para os catadores de materiais recicláveis.

As tecnologias sociais são metodologias reaplicáveis que se destacam pelo êxito na melhoria das condições de vida da população. Configuram-se como soluções participativas, estritamente ligadas à realidade local. Segundo Dagnino (2004, p. 194), são tecnologias "capazes de viabilizar economicamente empreendimentos autogestionários."

A construção de uma tecnologia social para geração de trabalho e renda se tornou um desafio para a universidade, principalmente em torno da sua relação com os catadores de materiais recicláveis. O ponto de partida para a construção do projeto foi a constituição de uma equipe que deveria definir, a partir de estudos realizados anteriormente, a área da cidade e o grupo com o qual se construiria o processo de intervenção.

Seguindo, em certa medida, as sugestões teóricometodológicas de Freire (1990), foram iniciadas visitas exploratórias como forma de identificar as organizações e lideranças populares da área delimitada. $\mathrm{Na}$ aproximação com o grupo the foi apresentado o Edital do CNPq e discutida a realidade dos catadores do município de Cruz Alta e do Núcleo Habitacional Santa Bárbara (NHSB).

À medida que se discutia a realidade $\mathrm{e}$ a equipe esclarecia os objetivos da intervenção, o método de trabalho a ser realizado ganhava contornos e se constituía um grupo que estaria junto na construção da proposta. Depois da síntese das discussões acerca da realidade dos catadores - feita pelos pesquisadores e pelo próprio grupo de catadores - foi elaborado o projeto Autogestão para geração de trabalho e renda com catadores de materiais recicláveis $(\text { Agetrec) })^{3}$.

Foi traçado como objetivo principal do projeto a construção de alternativas para geração de trabalho e renda e melhoria das condições de vida dos catadores a partir do desenvolvimento de cinco fases: fortalecimento da organização dos catadores, instalação de um entreposto, organização para o trabalho e participação social, construção de parcerias e consolidação da organização e fortalecimento da autonomia dos catadores.

A estratégia metodológica proposta para conduzir as ações do projeto foi a autogestão, sustentada por dois pilares de ação, quais sejam, formação política e capacitação para o trabalho, incluindo nesta metodologia o acompanhamento e a avaliação do 
processo de organização para geração de trabalho e renda com pesquisadores e catadores participantes.

Os processos autogestivos ou autogestionários implicam processos de organização social e econômica e incluem a divisão do trabalho, visto que se trata de processo produtivo. No entanto, não impõe a existência de uma hierarquia, tampouco diferença de poder. Os quadros hierárquicos não têm como função impor a vontade de um sobre o outro, pois na autogestão é o coletivo que delibera e decide. Nesta perspectiva, o saber é exercitado no coletivo, no qual se conhece a realidade, o que permite definir ações para transformá-la, como alerta Baremblitt (1996).

Para facilitar o processo de organização socioprodutiva, foi prevista a participação de integrantes do grupo de catadores em seminários e trocas de experiências com catadores da região, campanhas na rádio, elaboração e distribuição de panfletos informativos para a comunidade local e outras mídias.

Foi prevista no projeto a organização de eventos e oficinas com o objetivo de proporcionar o debate e a participação do coletivo. Técnicas de reuniões e plenárias foram projetadas para viabilizar a formação e capacitação dos pesquisadores e catadores. Também foram previstas visitas domiciliares para mobilização da população. Reuniões com entidades locais e com o poder executivo municipal foram planejadas para articular e inserir os catadores nos programas e projetos sociais desenvolvidos no município. Para a avaliação deste projeto, foram definidos indicadores qualitativos e quantitativos de avaliação em processo e avaliação final.

\section{Ações desenvolvidas e resultados alcan- çados}

Apesar de muitas vezes as condições para a realização das atividades propostas não terem sido favoráveis, pois geralmente o coletivo respondia aos interesses de outras entidades e grupos, no próprio coletivo foram definidos os problemas e as possíveis soluções. Assim, a atuação da equipe de pesquisadores esteve sincronizada com a realidade dos catadores, sem a preocupação de impor um ritmo à organização, e sim de orientar o processo e o tempo do grupo para que este se consolidasse e, com isso, favorecer a experimentação de outras formas de trabalho e de vida.

Durante o processo de intervenção, foram realizadas 92 visitas domiciliares no bairro e na região para mobilização e organização dos catadores. Na execução do projeto, foram realizadas mais de 90 reuniões. Algumas reuniões foram dirigidas à formação e capacitação dos catadores, privilegiando temas como a autonomia, a função social da atividade de coleta e a organização para o trabalho. Também foram desenvolvidos estudos e elaborados fôlderes informativos. Foram realizadas oficinas voltadas à produção, comercialização e viabilidade financeira de empreendimentos associativos.

Para mobilização das entidades e construção de parcerias, foram realizadas 25 visitas a entidades públicas e privadas, com o objetivo de apresentar o projeto e buscar parcerias para a destinação dos resíduos sólidos para os catadores. Ademais, foram promovidas reuniões e discussões com representantes do poder executivo local para inclusão dos catadores no programa Restaurante Popular da Segurança Alimentar e Nutricional (SAN) e no Programa Bolsa Família de Transferência de Renda.

Dentre os 105 catadores que participaram do projeto Agetrec, 67 eram mulheres e 38 eram homens. A idade variava de 18 a 60 anos, predominando aqueles entre 30 a 50 anos. Com relação à escolaridade, $80 \%$ dos catadores não concluíram o ensino fundamental. Muitos não sabiam ler nem escrever e menos de $2 \%$ concluiu o ensino médio. Moravam em casas cedidas e em estado de degradação e viviam de doações ou "biscates".

A participação dos catadores nas reuniões e oficinas, geralmente motivada pela expectativa de trabalho e renda, constituía-se em espaços de discussão sobre as trajetórias, geralmente comuns, de empregos sem vínculos formais, com baixa remuneração e sem direitos. Os catadores expressavam o inconformismo com as situações de riscos, preconceitos e humilhações às quais se submetiam ao realizar seu trabalho. Também era comum a manifestação de dificuldades em organizar um processo de trabalho de forma autogestionária, pois percebiam que continuariam sem proteção social e com rendimentos eventuais e incertos.

A formação de parcerias com entidades do município e região foi apontada como uma alternativa capaz de contribuir com a ampliação e expansão das atividades de coleta. Foram mobilizadas entidades públicas e privadas como bancos, correios, universidades, cartórios, empresas, estabelecimentos comerciais, escolas e igrejas. Muitas se manifestaram interessadas, mas somente três enviavam regularmente os resíduos sólidos descartados ao grupo de catadores - um banco estatal, uma universidade privada e uma escola pública.

Os resultados apresentados mostram o aprofundamento do conhecimento dos catadores e dos pesquisadores em suas relações com a realidade. Todas as fases da intervenção aconteceram simultaneamente. A todas as fases foi dirigida atenção e importância, visto que constituíam um processo interventivo, o qual teve o pretexto de saber em que consiste a realidade concreta dos catadores de materiais recicláveis, a partir da percepção que esses trabalhadores têm de si, do seu trabalho, da sua vida e da sociedade e de como constroem sua condição de sujeitos. 


\subsection{Fortalecimento da organização dos catadores}

A primeira fase do projeto esteve voltada para a organização do grupo de catadores constituído por moradores do NHSB, os quais faziam a coleta de forma individual e vendiam para atravessadores. Segundo os catadores, o armazenamento de materiais recicláveis, por não existir nenhum tipo de trabalho e organização, é realizado nos próprios domicílios. Essa situação ocasiona problemas de saúde e acidentes domésticos, tais como incêndios nas moradias. Já a comercialização caracteriza-se pela troca de recicláveis por leite ou outros alimentos com atravessadores ou intermediários. A venda individual e em pouca quantidade faz com que os preços levem os catadores a um nível de renda muito baixo.

Para mudar essa realidade, foi traçada como meta a promoção de articulação entre os catadores e as instâncias organizadas da região e do estado para potencializar o processo de organização, através da troca de experiências e de informação.

Um grupo de catadores passou a discutir a viabilidade da criação de uma associação ou cooperativa. Os catadores optaram pela criação de uma associação, visto que o processo de organização era recente e até então não haviam experimentado a possibilidade de geração de trabalho e renda de forma coletiva.

Após a elaboração de estatuto e da realização de assembleia geral, foi formada a Associação de Catadores de Cruz Alta (ACCA), com registro em cartório e cadastro em órgão competente. Também foi elaborado e aprovado o regimento interno, como forma de regulamentar a operacionalização do trabalho dos catadores associados.

Apoiadores do MNCR visitaram o grupo de catadores da ACCA, trazendo experiências sobre outras organizações de catadores. Foram realizadas análises de conjuntura para discutir as condições de trabalho dos catadores no município e região. Nesta ocasião foram definidas e distribuídas atividades para todos os catadores e também para a equipe de pesquisadores.

Nos encontros, através do uso de cartazes, eram exibidas as atividades e os nomes dos responsáveis por elas, para avaliar o andamento destas atividades e traçar novas estratégias. A partir dessas atividades, os catadores organizaram uma manifestação pública em frente à Prefeitura Municipal, com o objetivo de reivindicar ao Poder Executivo um espaço físico capaz de comportar a realização de atividades de separação, armazenamento e comercialização de materiais recicláveis. Na ocasião, foram distribuídos panfletos informativos sobre a importância da coleta seletiva e concedidas entrevistas na rádio e na tevê, com o propósito de informar sobre a realidade dos catadores no município.
Como forma de aproximação da luta e do conhecimento da realidade, os catadores participantes do projeto visitaram associações e cooperativas, para troca de experiências e articulação com outros grupos da região e do estado ${ }^{4}$.

\subsection{Instalação do entreposto}

A organização e o planejamento do processo de trabalho dos catadores se efetivaram a partir da instalação do entreposto de coleta, seleção, armazenamento e comercialização dos recicláveis. Os catadores constituíram um grupo permanente para acompanhar a instalação do entreposto e o prefeito municipal assinou um termo de concessão de uso de um prédio $^{5}$. Este espaço materializou a conquista do grupo de catadores para realização do trabalho coletivo.

Para viabilizar o trabalho dos catadores, foram adquiridos equipamentos e material permanente e de consumo, como prensa, balança, carrinhos, empilhadeira e outros. Os catadores acompanharam a aquisição tanto das máquinas quanto dos equipamentos de proteção individual (EPI's). As empresas fornecedoras foram convidadas a visitar o grupo de catadores e apresentar os equipamentos. As máquinas foram adquiridas de acordo com o previsto no projeto e com as necessidades dos catadores e passaram a ser utilizadas por eles.

$\mathrm{O}$ entreposto foi instalado para receber, separar, armazenar e expedir os materiais recicláveis coletados. Além de ser um local para separar e processar o material recolhido, esse espaço passou a funcionar como um centro de referência para a promoção da organização dos catadores e como espaço de formação e capacitação.

\subsection{Organização para o trabalho e participação social}

A capacitação para o trabalho, através da apropriação de conteúdos e do desenvolvimento de habilidades associadas à organização do trabalho coletivo e à autogestão associativa, envolveu atividades de coleta, seleção, armazenamento e comercialização de materiais recicláveis, nas dimensões técnica, ecológica e econômica. Destacou-se nesta fase o planejamento operacional para a organização do trabalho.

Através da realização de oficinas, foram abordadas as temáticas de autogestão, das dimensões administrativas e financeiras do empreendimento associativo, do coletivo e do poder de decisão, além da discussão de temas como custos, produção, organização do trabalho, rateio e prestação de contas. Foram criados instrumentos de controle da produção como planilhas de controle, fluxo de caixa e outros. 
O grupo de catadores se reuniu semanalmente para discussão das atividades e da auto-organização. O diálogo entre os catadores e seus pares provocou a apreensão da realidade de trabalho/desemprego à qual estão submetidos. Ao mesmo tempo em que reconheciam que não estavam sozinhos nesta atividade, percebiam que as mudanças seriam geradas a partir da criação de instâncias de resistência e luta.

As atividades realizadas nessa fase do projeto envolveram a escolha de representantes dos catadores para participarem de eventos na região, como forma de multiplicar a experiência. Foram organizadas atividades na Universidade de Cruz Alta para os catadores contarem sua experiência de organização social e econômica e com isso promoverem discussões acerca das condições de trabalho a que estão submetidos.

\subsection{Construção de parcerias}

A quarta fase do projeto contemplou a construção de parcerias com entidades públicas e privadas para a realização da separação dos resíduos e destinação aos catadores. Acompanhados pelos bolsistas, os catadores realizaram visitas às várias entidades. Foi criado um formulário com a definição dos dias e horários que os catadores passariam nas entidades para coletar o material reciclável.

As entidades públicas federais, de administração direta e indireta, foram visitadas e informadas sobre o Decreto n. 5.940, de 25 de outubro de 2006, o qual institui a separação dos resíduos recicláveis descartados na fonte geradora e a sua destinação às associações e cooperativas de catadores.

O grupo de catadores enquadra-se no artigo terceiro do referido Decreto, pois está formal e exclusivamente constituído por catadores que têm a catação como única fonte de renda, não possui fins lucrativos, possui infra-estrutura e apresenta sistema de rateio entre os associados.

A partir de visitas a entidades e empresas, foi formada a rede de parcerias, abrangendo também condomínios, comércios, escolas e comunidade. Muitas empresas do município contataram os catadores para saber se estavam organizados legalmente, ou seja, se a associação era uma entidade registrada com CNPJ e se era do seu interesse receber doações ${ }^{6}$.

\subsection{Consolidação da organização e autonomia dos catadores}

Esta última fase do projeto buscou a consolidação da organização e o fortalecimento da autonomia do grupo de catadores. Tratou-se, principalmente, de discutir com os participantes a continuação do processo pelo próprio grupo. Por se tratar de um pro- cesso autogestivo, desde o início os catadores foram chamados a participarem e decidirem.

É importante considerar que os catadores tiveram uma história de subemprego e desemprego. Portanto, a organização de forma autogestiva para gerar trabalho e renda deve ser um investimento de longo prazo. Além disso, por se tratar de uma proposta de aplicação de tecnologia social para gerar trabalho e renda, é necessário um período maior para que o grupo venha a construir saberes sobre o processo de produção e fazer com que esta produção lhe garanta melhores condições de vida. A despeito da disponibilidade dos catadores para discutir e decidir sobre as ações propostas, as decisões tomadas muitas vezes não foram colocadas em prática.

Entre 2006 e 2008 mais de 100 catadores participaram do projeto Agetrec. Porém, o número de catadores oscila de um mês para o outro. Por exemplo, num mês foi constituído um grupo formado por mais de 60 pessoas; no mês seguinte esse número foi reduzido à metade. Em períodos mais longos havia apenas 10 participantes.

Existiam no grupo aqueles que desempenhavam a atividade de catadores havia algum tempo e aqueles que se somavam a esses trabalhadores em função do desemprego. Isso provocou uma transição de pessoas dentro do grupo e dificultou a organização: muitas vezes um catador participava de uma assembleia e deliberava acerca dos seus interesses e dos interesses coletivos, mas em seguida ingressava em outra atividade (geralmente informal), ou, ao contrário, ingressava no grupo após as tomadas de decisão, não tendo, muitas vezes, a compreensão da dinâmica e da direção que o grupo havia tomado.

\subsection{Monitoramento e avaliação}

As ações destinadas a subsidiar a implementação do projeto, bem como seu monitoramento e avaliação, foram definidas a partir de três indicadores: de desempenho em relação ao processo auto-organizativo, de desempenho em relação à atividade de coleta seletiva e de resultados.

Para a avaliação do processo auto-organizativo, foi elaborado e discutido entre os participantes do projeto um roteiro de coleta de dados. Dentre um universo de 57 catadores, 13 responderam às questões relacionadas à avaliação. Dentre os entrevistados, 92\% disseram participar dos espaços de discussão promovidos através do projeto. Todavia, quando indagados sobre a participação nas tomadas de decisão, somente $75 \%$ afirmaram que opinavam e deliberavam sobre a organização. Para $87 \%$, o grupo trabalhava de forma organizada, e $75 \%$ entendiam que as atividades eram distribuídas de forma equitativa. Para os catadores, existiam muitas dificuldades em relação ao processo de 
organização para o trabalho, relacionadas à falta de humildade, de compreensão e de solidariedade dos colegas, o que implicava brigas por motivos alheios à organização produtiva. Os catadores entendiam que o trabalho em grupo exigia paciência, convívio e perseverança.

No que diz respeito à apropriação de conhecimento sobre a organização do processo de traba1ho, $50 \%$ dos catadores afirmaram ter se apropriado dos instrumentos de registro. Entretanto, 87\% disseram não saber como organizar a divisão da produção. Para $87 \%$ dos trabalhadores, as mudanças em relação às condições de trabalho eram evidentes e consideraram que a partir da inserção no grupo passaram a conhecer as instâncias organizadas da categoria e participar de atividades relacionadas à geração de renda.

No que toca às mudanças na quantidade da produção, os catadores observaram uma grande fragilidade, relacionada principalmente ao fato de que muitas das pessoas que participavam do processo viam o trabalho do catador como um "bico". O preconceito da sociedade associado às dificuldades do exercício de coleta eram elementos que contribuíam para isso.

A comercialização permaneceu sendo feita com o atravessador, pois, como a produção era pequena e a coleta seletiva ainda não fora implantada pelos gestores públicos, nenhuma empresa comprava o material no município. Mesmo assim, 75\% dos catadores afirmaram ter conquistado melhores preços depois da aquisição dos equipamentos e da formação da associação.

Para 92\% dos catadores, as parcerias estabelecidas com as entidades públicas e privadas foram alternativas para o aumento da produção. $\mathrm{O}$ uso de EPI's diminuiu os riscos e a insegurança no traba1ho: $62 \%$ afirmaram que as condições de trabalho melhoraram, conquanto ainda existissem riscos. Constatou-se que somente $62 \%$ utilizavam os EPI's adequadamente. Para os catadores, a utilização adequada do maquinário, bem como dos EPI's, depende de mais tempo.

As condições socioeconômicas das famílias que participaram do projeto continuaram precárias: $80 \%$ continuaram com uma renda inferior a um salário mínimo. Para os catadores, a organização para o trabalho era importante, mas se mostraram decididos a não fazer do trabalho seu maior investimento.

Muitas famílias possuíam cadastros em programas sociais como o Programa Bolsa Família, além de vínculos com equipamentos sociais como igrejas, pastorais, associações de bairro, o que lhes proporcionava condições de subsistência. A inclusão dos catadores no Programa Restaurante Popular, da Segurança Alimentar e Nutricional (SAN), foi conquistada a partir da organização da associação.

\section{Discussão da/pela experiência}

A experiência de organização de processos socioprodutivos com catadores de materiais recicláveis mostrou as fragilidades e as dificuldades enfrentadas por esses trabalhadores, na medida em que os recursos investidos para instauração de espaços de trabalho para essa população são mínimos. Não bastassem as dificuldades relacionadas ao pouco investimento, os catadores não têm estabilidade na sua ocupação nem nos seus rendimentos, além de ficar à mercê da boa vontade da sociedade e da exploração da indústria da reciclagem.

Mota (2002, p. 10), ao abordar o desenvolvimento da indústria de reciclagem e as inflexões que as suas práticas produzem na esfera do trabalho e da ação do Estado, diz que o crescimento da atividade de catador nos centros urbanos está relacionado ao lugar que este trabalhador ocupa no processo de produção da indústria de reciclagem, uma vez que "as empresas o desconhecem como partícipe do seu processo de trabalho, embora o integre ao processo geral de produção dos reciclados."

Já o Estado, avalia Mota, sob o discurso da preservação ambiental ou com a justificativa da necessidade de assegurar ocupação e renda, tem promovido a inserção produtiva desses trabalhadores, o que acaba muitas vezes por "garantir a qualidade das mercadorias exigida pelas indústrias" ou então simplesmente se apropria "do trabalho do catador ao integrá-lo de forma precária nos serviços de limpeza urbana."

O estatuto de trabalhador não garante aos catadores condições mínimas de trabalho e vida, mesmo quando a atividade constitui-se na única forma de subsistência. Marcados pelo desemprego e por terem se tornado não empregáveis, os catadores sobrevivem em condições mínimas de saúde, de moradia e de alimentação.

A escolha da autogestão como estratégia metodológica para condução da intervenção aqui apresentada possibilitou o exercício coletivo do saber e gerou o conhecimento acerca da realidade, permitindo a definição de ações para sua transformação. Contudo, se, por um lado, os catadores experimentaram protagonizar a organização socioprodutiva, através de processos de autogestão e participação social, por outro, trabalharam sem o exercício dos direitos trabalhistas.

Antunes (2006), ao abordar o contexto atual do trabalho, destaca a proliferação de distintas formas de empreendedorismo, cooperativismo, trabalho voluntário e outros. Para o autor, longe daquilo que foram as cooperativas em sua origem, construídas como instrumentos de luta e defesa dos trabalhadores, hoje são formas precárias que visam à redução e destituição dos direitos do trabalho. 
Ao se referir à subalternização do trabalho à ordem do mercado e à desmontagem de direitos sociais e trabalhistas, Yazbek (2001, p. 35), lembra que “a proporção de trabalhadores brasileiros que está fora do mercado de trabalho e, portanto, sem garantia de proteção social cresce continuamente e hoje ultrapassa mais da metade da população economicamente ativa."

Romani (2004), ao analisar experiências desenvolvidas nas Regiões Sul, Sudeste, Norte e Nordeste do Brasil, destaca as dificuldades enfrentadas pelos catadores de materiais recicláveis de Belém do Pará, Belo Horizonte, Porto Alegre, Recife, Rio de Janeiro e São Paulo. As dificuldades enfrentadas pelos catadores dessas cidades são semelhantes àquelas dos participantes do Agetrec: constituição de grupos organizados de catadores e continuidade de ações e compromissos estabelecidos, bem como garantia de envolvimento dos órgãos administrativos e operacionalização da coleta de recicláveis. Somam-se a essas dificuldades as condições de vida e trabalho dos catadores: baixa escolaridade, necessidade de desenvolver diversas atividades para sobreviver e o trabalho sem proteção social. Percebe-se que o grande desafio nos processos de organização socioprodutiva com catadores de materiais recicláveis é combinar a criação dos postos de trabalho com a possibilidade de participação dos catadores na gestão dos resíduos, para que estes trabalhadores não se vejam como beneficiários, mas como responsáveis por suas conquistas e conscientes de que sua luta precisa continuar avançando.

\section{Considerações finais}

Neste percurso de dois anos, as ações desenvolvidas neste projeto buscaram apoiar a organização socioeconômica dos catadores para romper com seu isolamento, a partir da articulação com outros grupos e instâncias representativas. Nesses processos de participação os trabalhadores puderam se apropriar criticamente da realidade de desemprego, de dependência de programas governamentais ou filantrópicos e desvelar as determinações da realidade em que vivem.

Filhos de analfabetos que não conseguiram inserção no mercado de trabalho, muitas vezes por não saberem nem mesmo seguir instruções, os catadores expressam a expansão da população que se tornou não empregável e que não encontra um lugar na sociedade que lhe assegure condições dignas de trabalho e de proteção social. Sem garantias ou vínculos, os catadores tornam-se cada vez mais pobres.

As políticas de trabalho e renda não alcançam a realidade dos catadores ${ }^{7}$. Na verdade, aos catadores são dirigidas ações no campo das políticas de inclusão e não no campo das políticas públicas de trabalho e renda. Trata-se de ações focalizadas, dirigidas aos grupos vulneráveis como desempregados, mulheres e jovens.

Interesses individuais, restrito exercício de participação, oportunismos, presença de práticas clientelistas e a demanda por um "salvador" capaz de resolver todos os problemas relacionados à organização dos catadores foram forças presentes no processo de realização desse projeto. $\mathrm{O}$ fato de os catadores não possuírem um histórico de participação em movimentos sociais dificultou a organização destes trabalhadores em prol de interesses coletivos. Contudo, essa dificuldade passou a ser superada após a criação de espaços de discussão e o intercâmbio de experiências proporcionadas pelos encontros promovidos na região e no estado. A articulação com outros grupos contribuiu para a constituição de uma identidade coletiva para o grupo de catadores de materiais recicláveis de Cruz Alta.

As ações desenvolvidas com catadores no município ainda são isoladas, mas remetem à articulação destes trabalhadores com instâncias organizadas para reivindicações e luta por melhores condições de trabalho e vida.

Mesmo diante de contradições relacionadas às formas de gestão associativas, muitas vezes entendidas como conquistas próprias de cada indivíduo, disposto a sobreviver através da criação de formas "alternativas" de trabalho, engendradas por si mesmos, ou então fundamentadas pela perspectiva de desenvolvimento social como investimento para a ampliação das "capacidades” de participação e superação da pobreza pelos próprios pobres, as ações executadas e os resultados alcançados nesta intervenção apontam para as reivindicações dos catadores por um projeto social e político de transformação das formas vigentes de sociabilidade. Um projeto societário que se faça na luta dos grupos e movimentos sociais que, diante das novas expressões da questão social, forjam instrumentos de enfrentamento, com limites, mas também com possibilidades de interferir como sujeitos políticos na construção da sociedade. 


\section{Referências}

ANTUNES, R. As formas contemporâneas de trabalho e a desconstrução dos direitos sociais. In: SILVA, M. O. S.; YAZBEK, M. C. (Org.). Politicas públicas de trabalho e renda no Brasil contemporâneo. São Paulo: Cortez, 2006, p.41-51.

BAREMBLITT, G. Compêndio de análise institucional e outras correntes. Rio de Janeiro: Rosa dos Tempos, 1996.

DAGNINO, R. A tecnologia social e seus desafios. In: FUNDAÇÃO BANCO DO BRASIL. Tecnologia social: uma estratégia para o desenvolvimento. Rio de Janeiro: 2004. p. 187-210.

FREIRE, P. Criando métodos de pesquisa alternativa. In: BRANDÃO, C. (Org.). Pesquisa participante. São Paulo: Brasiliense, 1990, p. 34-41.

MARTINS, J. S. A sociedade vista do abismo: novos estudos sobre exclusão, pobreza e classes sociais. Petrópolis: Rio de Janeiro, 2002.

MOTA, A. E. Entre a rua e fábrica: reciclagem e trabalho precário. Temporalis, ABEPSS, Brasília, ano 3, n. 6, 2002.

MOTA, A. E.; AMARAL, A. S. Reestruturação do capital, fragmentação do trabalho e Serviço Social. In: MOTA, A. E. (Org.). A nova fábrica de consensos. São Paulo: Cortez, 2006. p. 23-44.

PRADO, M. Estamira. Documentário. Brasil, 2004.

ROMANI, A. P. O poder público municipal e as organizações de catadores. Rio de Janeiro: IBAM/DUMA/ CAIXA, 2004.

SANTOS, B. de S. Lixo e cidadania. Revista Visão (Portugal), 27 set. 2007. Disponível em: <http:// www.movimentodoscatadores.org.br/artigos $>$. Acesso em: 30 set. 2007.

SANTOS, G. S. (Org.). O estado da arte da formação do trabalhador no Brasil: pressupostos e ações governamentais a partir de 1990. Cascavel: Edunioeste, 2007.

VARDA, A. Les glaneurs et la glaneuse. Filme. França, 2000.

YAZBEK, M. C. Pobreza e exclusão social: expressões da questão social no Brasil. Temporalis, ABEPSS, Brasília, ano II, n. 3, 2001.

. Os caminhos para a pesquisa no Serviço Social. Temporalis, ABEPSS, Recife, UFPE, ano V.n. 9, 2005.
YAZBEK, M. C.; SILVA, M. O. S. Das origens à atualidade da profissão: a construção da Pós-Graduação em Serviço Social no Brasil. São Paulo: Cortez, 2005.

\section{Notas}

1 Trata-se de uma intervenção que envolveu catadores e pesquisadores na elaboração e execução do projeto Autogestão para geração de trabalho e renda com catadores de materiais recicláveis (Agetrec). O projeto foi financiado pelo Conselho Nacional de Desenvolvimento Tecnológico (CNPq)e executado pelaUniversidade de CruzAlta(Unicruz), em parceria com o Movimento Nacional de Catadores de Materiais Recicláveis (MNCR) e com o Poder Executivo de Cruz Alta/RS. O projeto foi orientado pela professora Mari Aparecida Bortoli, com a colaboração das professoras Enedina Maria Teixeira da Silva e Rosane Rodrigues Felix. Foram bolsistas do projeto: Fernanda Bortolini Klein,Adriano Christ Guma, Aline Mello Paes e Jaqueline Pereira Paes. Colaboraram com o desenvolvimento do projeto 105 catadores. Os dados foram coletados de acordo com a Declaração de Helsinque V, 1996, e a Resolução 196/96 do Conselho Nacional de Saúde. Na ocasião do envio do projeto ao CNPq não foi solicitado parecer de aprovação do Comitê de Ética em Pesquisa. No entanto, todo o processo de intervenção foi construído com os catadores e professores, a partir de reuniões para discussão e sistematização, registradas e datadas em atas com assinaturas dos participantes. O projeto foi submetido para Declaração de Parceria à Equipe de Articulação Nacional - Movimento Nacional de Catadores de Materiais Recicláveis - Regional Sul e ao Poder Executivo Municipal de CruzAlta/RS.

2 Em 2005 o Ministério da Ciência e Tecnologia (MCT), por intermédio do CNPq, lançou o Edital n.18/2005, prevendo recursos para apoio a projetos de tecnologias sociais para inclusão dos catadores de materiais recicláveis.

3 Em outubro de 2005, o CNPq aprovou recursos financeiros para execução do projeto e disponibilizou bolsas de estudo. Duas bolsas foram dirigidas aos integrantes do grupo de catadores para articulação e intercâmbio de informações com outras instâncias organizativas e outras duas dirigidas a estudantes. O valor aprovado foi de R\$91.406,80, além de quatro bolsas nas modalidades ATPA ATPB. Modalidade: Auxílio Integrado. Processo: 553727/2005-2.

4 Destaca-se a participação dos catadores nos seguintes eventos e atividades: Fórum Regional deEconomia Solidária, Plenária Regional do Noroeste sobre Economia Solidária, Conferência Estadual de Economia Solidária, Revisão do Plano Diretor de CruzAlta, JornadaAmbiental da Região do Alto Jacuí, Feira das Profissões, Congresso Estadual do MNCR. Foram realizadas visitas às organizações de catadores dos municípios de Júlio de Castilhos, Tupanciretã, Erechim, Cachoeirinha e Porto Alegre. 
5 Através do Decreto n. 0138, foi concedida autorização de uso de um prédio para a realização do projeto. A estrutura física constitui-se numa área de $192,50 \mathrm{~m}^{2}$, cedida pelo Poder Executivo Municipal.

6 Na verdade, as empresas querem se enquadrar num padrão de qualidade que lhes garanta a gestão ambiental para o certificado ISO 14.000.

7 As políticas passivas, ao atuarem no provimento de assistência financeira temporária ao trabalhador, através do abono salarial ou do seguro-desemprego, não podem ser acionadas pelos catadores de materiais recicláveis: eles não experimentam as condições de desempregados, visto que, ao trabalharem como catadores, não estão em condições de trabalho formal. Portanto, ao não gerarem contribuição social, não têm assegurados esses benefícios. As políticas ativas, por sua vez, buscam aumentar as oportunidades de trabalho e renda e garantir a subsistência daqueles trabalhadores oriundos do setor formal. Os programas de investimento estão voltados à capacidade produtiva da economia e à dotação de capital social básico para a geração e manutenção de empregos.

\section{Mari Aparecida Bortoli}

Doutoranda em Serviço Social pela Pontifícia Universidade Católica do Rio Grande do Sul (PUC-RS) Orientadora: Profa. Dra. Gleny Terezinha Duro Guimarães

\section{PUC-RS}

Programa de Pós-Graduação em Serviço Social Av. Ipiranga, 6681

Partenon

Porto Alegre - Rio Grande do Sul

CEP: 91530-000 